Coolabah, Nr 29, 2021, ISSN 1988-5946, Observatori: Centre d'Estudis Australians $i$ Transnacionals / Observatory: Australian and Transnational Studies Centre,

Universitat de Barcelona

\title{
Enigma of the Dark: Reflections while Researching Journalism and the Claremont Serial Killings
}

Mary-Anne Romano

Curtin University WA

mary-anne.romano@postgrad.curtin.edu.au

\begin{abstract}
Copyright $\left({ }^{\circ} 2021\right.$ Mary-Anne Romano. This text may be archived and redistributed both in electronic form and in hard copy, provided that the author and journal are properly cited and no fee is charged, in accordance with our Creative Commons Licence.
\end{abstract}

\begin{abstract}
After almost 25 years of mass media coverage on the Claremont Serial Killings, Perth audiences were informed in December 2020 that Bradley Robert Edwards would serve two life sentences for murdering two of the young women. This article draws on interviews with journalists to discuss media practices in the case that shocked Perth while shaping audience understandings of women as victims. The article describes how the term 'serial killer' came into use to bolster the importance of Western Australian news; how the status and resources of victim's family influenced media coverage and, consequently, the police investigation; and, how the position of a journalist as an unbiased observer became untenable in the case.
\end{abstract}

Keywords: Claremont Serial Killings; journalism as ritual; media coverage 
Western Australia tends not to be a place where people come by accident. It is a conscious decision; whether it is to be with family, a long holiday, a place to work or in more recent times, to live life without the constraints of masks, lockdowns and the constant rhetoric of life during a pandemic. There has not been any COVID related community transfer here in over nine months. Landlocked between desert and ocean, isolation has been part of our narrative from the early days of colonial settlement, when British capitalists and supporting troops invaded Indigenous country and transported convicts to Perth to build the infrastructure for emerging colonial industries and government institutions (Kerr, 2015; Statham-Drew, 2003). Many Western Australians jokingly enjoy referring to remoteness as part of their identity; ask anyone from Perth to tell you a surprising fact about our capital city and they will most likely tell you that "we are the most isolated city in the world'. It is not true though, Perth actually comes in fourth; Iquitos in Peru has earned that honour (Gill, 2015), but no one here will tell you otherwise. Also, by listening carefully, you may hear the longstanding - but often forgotten - discourse of Indigenous connection here to trade routes and social contacts in other nearby countries.

Our singularity around our identity of isolation and remoteness is what makes us unique. Unlike our (much smaller) east coast cousins, Western Australia geographically makes up nearly a third of the Australia landmass, with our vast commodities, including mining and agricultural goods, not only being exported overseas but to our counterparts on the east. Our moniker of being the 'engine room of the Australian economy' (Wyatt, 2019) is not lost on us, in fact there is almost a perverse enjoyment of knowing that the national economy could be left floundering if we happened to up and leave.

This detachment has also translated into how we view our capital city, Perth and the surrounding areas. Our seclusion can be seen as insular, in fact, rhetoric in Perth still describes us as a 'big country town'; more laid back, safer and less crime than the giant cities of Sydney and Melbourne on the eastern seaboard. What people sometimes fail to mention, either purposely or unintentionally, is that Perth has been affected by a number of high-profile crimes which have altered its perception of itself and its community.

More than two decades ago, on Australia Day 1996, the disappearance of an 18-year-old woman from an affluent suburb in Perth, would mark the beginnings of the Claremont Serial Killings. The longest and most expensive unsolved murder investigation in Australian history followed, with the killings affecting the psyche of the Perth community. The community of just over 1.2 million (Australian Bureau of Statistics, 1996) was "king-hit by a menace it couldn't see" (Marshall, iii). The disappearance of Sarah Spiers from Claremont in January 1996, followed by the disappearances of Jane Rimmer, 23 and Ciara Glennon, 27, in 1997 and discovery of Rimmer and Glennon's bodies, has become part of Perth's crime narrative.

Bradley Robert Edwards, 52, was arrested and charged in December 2016 with the wilful murders of Jane Rimmer and Ciara Glennon as well as charges related to two sexual assaults in 1988 and 1995. Then, in February 2018, Edwards was charged with the wilful murder of Sarah Spiers even though her body has never been found. Edwards pleaded not guilty to the murders. The judge-alone trial before Justice Stephen Hall, ran from November 2019 until June 2020 in the Western Australian Supreme Court, and according to the Western Australian Department of Justice, cost \$11 million, which is believed to be the most expensive in Western Australian history. 
In late September 2020, Edwards was found guilty of the wilful murders of Jane Rimmer and Ciara Glennon but acquitted of the murder of Sarah Spiers. On a side note, Edwards pleaded guilty to five charges related to the 1988 and 1995 sexual assaults at a pre-trial hearing in the month before his trial began. Two days before Christmas 2020, Edwards was sentenced to a total of 113 years, which included two life sentences of 40 years for each of the murders. He will not be eligible for parole for a minimum of 40 years - the longest ever non-parole period in Western Australian judicial history.

Semi-structured interviews have been applied in this study to understand the complex behaviour of journalists through multiple sources. The plan has been to interview at least ten journalists from the Australian Broadcasting Corporation (ABC) and SevenWest Media, in particular. To date seven journalists have been approached for interview; four have accepted (one from The West Australian and two from Channel 7 News Perth, one from the ABC and an additional one from another news organisation), two have declined and the investigator is awaiting a response from several others.

For this article, data is analysed from interviews with journalists who worked on the case as it emerged into the media. They include Rex Haw (Channel 9 News Perth and Channel 10 News Perth), Torrance Mendez (The West Australian) and John Townsend (The West Australian). This article also refers to the researcher's conversation with a fourth journalist who refused to be interviewed but who, generously, has granted consent for including their reasoning for the refusal in this article and subsequent work. Their reasoning provides insight into the impact the case has had on journalists who worked on it.

After the interviews, data was coded, arranged into categories pointing to significant concepts and emerging research themes were identified. These themes include why some journalists are reluctant to recall their work on the case; journalist's desire to take on additional 'roles' beyond just being the story teller; use of the term 'serial killer'; a culture of trying to outdo east coast news media; and, why the disappearance and murder of Ciara Glennon appeared to take the case to new levels.

This sections below will discuss findings from the analysis of interviews with journalists who worked on the emerging news story of the Claremont serial killings. These interviews were undertaken as part of a $\mathrm{PhD}$ project on journalistic practices in the case which includes interviews with other journalists and media participants as well as analyses of newspaper articles, television news broadcasts and a recent audio podcast series.

The disappearances and murders were especially formative for the researcher, as I entered womanhood in Perth within this context. I was among a whole generation of young people (best identified as those in the late Generation X phase) who were coming of age as the police incidents became news and were legally able to enter night clubs and bars when the sensational news story emerged just before mobile phones became accessible to the average consumer. This meant we relied on lifts to and from home from friends, catching a taxi (if money was available at the end of a night) or walking home, which was a relatively common sight in the early hours of a weekend night in Perth at the time. 
The subheadings included in this article have been taken directly from headlines used in The West Australian newspaper from after Sarah Spiers disappearance until just after the discovery of Ciara Glennon's body. Headlines set the tone for an article and are usually picked from the most newsworthy point regarding the story. Headlines can determine how many readers you will get, can change the way the audience reads the article and in the case of this larger project, remembers it. Psychologists have long reasoned that first impressions do count - what we see, hear, feel and experience when we first chance upon something, influences how we process it. In this case, the headlines can influence an audience's perception to the narrative and draw attention to aspects that can be inaccurate (Ecker et al., 2014).

'We’ve had Enough!' (Mallabone, 1997)

Writer David Whish-Wilson (2013a) argues these events have shaken Perth's public to its core. This sentiment has also been reflected by Western Australian lead state prosecutor Carmel Barbagallo, who, in her opening address to the court on 25 November 2019, explained how profound the impact of the disappearances and murders had been on an entire generation in Perth:

In a 14-month period in the mid-1990s, three young, bright, beautiful women vanished off the streets of Claremont under the cover of darkness... going out in Claremont to have an enjoyable night out with a few drinks in the company of friends and then making their way home safely, no matter how they chose to get home, or the darkness of the hour (McNeill, 2019).

How could three young women disappear from an upmarket nightspot without anyone seeing anything? The cases had remained unsolved for more than two decades and have become the subject of morbid fascination and speculation. Marshall (2007) describes Perth in the early years of the investigation:

A city [that has] descended in the twilight world of outright panic and bedlam. The shockwaves are felt throughout Perth, permeating the press ... politicians and police. Perth has reverted to the horrific, dark days when serial killer Eric Cooke indiscriminately ran amok in suburbs near Claremont, killing its beautiful young women (Marshall, 2007: 66).

The Claremont murders became public folklore, as did another case of serial murder 30 years earlier. Eric Edgar Cooke, the last man hanged at Fremantle Prison in 1964, commenced his murder spree of five people in Perth's wealthy inner-western suburbs on Australia Day in 1963, terrorising Perth with his random acts of violence. As many writers and commentators of the time suggest, Perth, with its small size (in 1963, Perth's population was approximately 450,000), isolation from other Australian capital cities, has always been small enough that dynamic people, such as serial killers and murderers, can have a disproportioned effect on decision making, particularly by police and politicians, and create certain modes of behaviour from the public (Drewe 2003; Whish-Wilson, 2013b). The Claremont Serial Killer was seen as enough of a real threat for the public, particularly women, to change their social behaviours, and to result in a proliferation of news coverage on the killings and its influence on the culture of Perth. 
'Woman missing: serial killer fear' (Morfesse, 1997)

The study of serial killers has included biographies of offenders and criminological analyses of the causes of their behaviour (Douglas and Olshaker, 2017). While serial killing is statistically rare (Schlesinger, 2001), it nonetheless has a significant impact on society; one that for the majority of people is only known and felt through news coverage and other mediated events. In this research, the Claremont Serial Killings are analysed as a series of media events with a focus on furthering understandings of the concept of journalism as ritual (Curran and Liebes, 2002).

This research considers the symbolic systems and rituals by which journalists maintain their authority as the voice of events in the public domain, and how that affects the public. The inspiration for this work comes from research, particularly during the 1970s (Cohen, 1972; Hall et al., 1978; Tuchman, 1978), where an expansion of the sociology of culture and journalism led to an expansion of understandings of journalistic practices and research begun on journalism as ritual. The aim here is to view journalism, ritual and culture as an interrelated web within society. This research contributes to the development of understandings described above by examining the rituals of newspaper and television reporting over a period when newsrooms have merged or got smaller, lines have blurred between advertorial and editorial, and editorial is responding to the rise of social media (Couldry, 2013).

The concept of ritual has been addressed in journalism studies by scholars (Couldry, 2005; Coonfield and Huxford, 2009) looking to understand the symbolic power of the media to direct public attention, define issues, and cause either social cohesion or dissolution. Media rituals performed in and through news coverage indicate social norms, common and conflicting values, and different ways of being included. The idea of ritual in journalism is related to discussions around the societal power of journalism as an institution, the ceremonial aspects of news coverage (in this case, around serial murders) and the different techniques journalists use to "make the news" and "construct reality" (Bell, 2009). Journalism does more than merely cover events or chronicle history - it provides a mediated space for audiences and publics that both allows and extends rituals that can unite, challenge, and affect society.

A ritual view of journalism focuses on a different range of problems in examining a news text. It will, for example, "view reading news less as sending or gaining information and more as attending a mass, a situation in which nothing new is learned but in which a view of the world is portrayed and confirmed" (Carey, 1975: 20). As Carey elaborates (1975: 21), "news reading, and writing, is a ritual act, and a dramatic one". What is displayed before the audience is not pure information but a portrayal of the contending forces in a particular context. As readers make their way through the news they engage in a continual shift of roles or dramatic focus. In this way, news can be seen as not only imparting information but also as a representation of a society's shared beliefs.

If we apply this ritual view to what newsmakers choose to include as news, then we must conclude that a journalist's political attitudes, values and opinions as well as their personal experiences in life, exert an influence on their work, regardless of the standard 
values or criteria (Conley and Lamble, 2006) applied to news. Relooking at studies of journalism through a ritual model, as this research proposes, aims to not only grasp this process more firmly, but to provide a way in which to rebuild a model of and for communication that could be of value in reshaping our collective culture.

\section{'Maniac feared as crimes list grows'}

Professional roles in journalism research have been well studied, mostly from the perspective of studies on regulating standards and around the conception of roles in journalism. To date, research on professional roles has analysed the different roles that journalism normally fulfil (Christians et al, 2009), as well as the roles that journalists give more credence to when working in different political, cultural, and technological circumstances (Willnat et al., 2013). However, less attention has been given to the study of these roles in both news decisions and the news stories that reach the public (Mellado, 2015).

Journalism culture implies a particular set of ideas and practices by which journalists legitimate their role in society and render their work meaningful. Understanding how journalists perceive their roles is imperative for this study because the understanding of journalistic culture, for example how journalists interpret news events and how journalists perform their work, may identify different perspectives of journalism for reporting on different types of events.

Scholars have noted that journalists regularly use the methods of narrative storytelling and personalisation to find lessons in the news (Kitch, 2002). Journalism practices and methods are essential not only for understanding the elaborate subtleties by which the news works, but for understanding journalism's central part as a primary receptacle of collective memory in every society it finds itself.

"What is more, journalism itself is full of the past" (Kitch, 2002: 61). Many journalism researchers have found that reporters tell stories about current events by using culturally iterative archetypes and descriptions in their work. Oft quoted as the first draft of history, journalism has had a love/hate relationship with the notion that it is adding to the collective memory of society. Journalism appears to want to fit more comfortably as contemporary, unique, instantaneous and timely. However, journalism provides a public archive on which those who work in the media can draw, republishing previous photographs or texts and reusing them for their lasting or contemporary significance. In doing so, they reshape as well as revisit the past. The "newer elements contextualise the past within the present and the future within the past, creating a narrative path with meaning" (Kitch, 2002: 6011).

\section{Findings from interviews}

During interviews, the journalists were questioned on a wide variety of issues related to the Claremont case, including what role they were in at their workplace during the case, how they perceived other journalists were working the story, the opinions about how the 
victims were portrayed in the media and the effect it had on Perth as a whole, keeping in line with the themes around journalism practices, ritual and memory. A number of research themes surfaced through the interview process and analysis of interview responses. These themes include why some journalists are reluctant to recall their work on the case; journalist's desire to take on additional 'roles' beyond just being the story teller; use of the term 'serial killer'; a culture of trying to outdo east coast news media; and, why the disappearance and murder of Ciara Glennon appeared to take the case to new levels.

One of the journalists who declined the invitation to take part in the study, did make contact to explain why they did not want to take part. The journalist will remain anonymous but they have granted consent to include our conversation in this article and subsequent work. This particular journalist wrote a large number of articles over the past two decades on the disappearance and murders of Sarah Spiers, Jane Rimmer and Ciara Glennon. While they did not want to take part in the study formally, they did indicate that reporting on the case had a profound effect on them personally, particularly once they had children of their own. Journalist John Townsend, from The West Australian, who covered general news at the time of the disappearances and murders, was more philosophical in his recollection.

I mean the reality of journalism, you have to do uncomfortable things, you have to speak to traumatised people, or do things on deadline or where there's a risk to your sanity or a threat to your health... I don't know why people [or organisations] don't want to be investigated, but I can understand for a lot of people, they've moved on... I'm in exactly the same boat. I didn't have kids [at the time] and now we do, we've got a family and it's absolutely critical. But I can understand that... (Townsend, personal communication, July 13, 2020).

The ability to compartmentalise the information about the case, both the published information and information gleaned from other journalists and police sources, was something journalists relied on, particularly early on in the case. A lot of the information coming from these sources was deemed to be unpublishable due to its content which would upset both the public and in particular, the families of the women.

Furthermore, the anonymous journalist also mentioned how coverage of the women "completely overtook the news coverage in Perth and once Ciara Glennon's body was found, and the police used the words 'serial killer', it went into overdrive". (Anonymous, personal communication, 20 February, 2020).

These comments have been echoed by the other journalists who have been interviewed to date. Torrance Mendez, who worked at The West Australian from 1990 until 2016, said the coverage became "feverish", but was coupled with an awful realisation.

It was feverish. That's the best way to describe it. People were jumpy... And there was a glumness [other journalists] was sad, and it went quiet and people were looking at each other and fearing the worst, but by the same time, you wanted the worst to come out so that you'd get a good run at it, to have it published for the next day... There was this - it was a disappointment, because although the newspaper would sell handsomely the 
next day, the awful truth was dawning on a lot of people that we had a serial killer. (Mendez, personal communication, July 12, 2020)

The term 'serial killer' had not been used in the media in Western Australia since the murders perpetrated by the Birnies in the early 1980s or the legendary murder spree and subsequent other killings by Cooke, referred to earlier in this article. David and Catherine Birnie were a couple from the Perth southern suburbs, who, over a five-week period in 1986, murdered four women ranging in age from 15 to 31 , and attempted to murder a fifth. It was this fifth victim, seventeen-year-old, Kate Moir, who escaped via a window from the Birnie's home and ran into a local vacuum cleaner shop informing the owner she had been raped. There is speculation that the Birnies were responsible for a number of disappearances of women as early as 1980, but have never been proven. David Birnie died by suicide in prison in 2005 and Catherine Birnie is currently in prison. In 2009, after her first parole application was declined, her case papers were marked "never to be released" by then Western Australian Attorney General Christian Porter.

Perhaps it is indicative of the overabundance of coverage the story will attain if using the phrase, but if the Federal Bureau of Investigations definition is what is deemed as definitive, then why not call it by its name? Previous definitions of serial murder specify a certain number of murders, generally varying from two to ten victims, and also require a period of time between the murders. As Morton (2005) suggests in the FBI publication Serial Murder: Multi-Disciplinary Perspectives for Investigators, serial murder also requires a temporal separation between the murders, such as a separate occasion, cooling-off period, or an emotional cooling-off period. All these cases fitted into this definition.

Since 2005, the FBI suggest the inevitable public reaction of the term 'serial killer' should be proactive from law enforcement. In fact, if the media link cases and use the term, then investigators should proactively release information, respond quickly and use the opportunity to gain an investigative advantage. By the time Jane Rimmer's body was found in June 1996, the term 'serial killer' was used unofficially by the media, but not by the Western Australian police (WAPOL). In fact, they made a pointed action in not using it, which journalists retrospectively suggest they should have followed, considering the previous experiences in Perth:

We [The West Australian] weren't the first cab off the rank, where possibly if we had this culture [as we do now], we should have done ... from what I can see, there have been three big serial murders in Perth ... so there was Cooke, and that introduced a terror to Perth society ... it was a coming of age ... the second was the Birnies and that was absolutely horrific where people were being picked up and then used as sex slaves and then killed ... and then there was the Claremont serial killings. Of these three cases, I would submit that the Cooke slayings did not capture worldwide imagination. The Birnies did. Why? Husband and wife, man and woman, sex, and the sheer scale and the horror ... but the media did not exist then to promote that story in that way and the third was the Claremont case, three pretty girls taken from a nightlife district and for decades the perpetrator is not identified. (Mendez, personal communication, July 12, 2020) 
Rex Haw, a former journalist from Channel 9 News Perth and 10 News First Perth was reflective in his reasoning behind the use of the phrase. When he was working on the east coast of Australia earlier in his career, it was commonplace for journalists to try and link murders, as a way to get extra leverage from a story or to at least get police to comment; either way, the media outlet gets another story to publish:

The Perth media and police treated the Claremont serial killer stories, the whole case, a lot differently than the same story would've been covered if it had been in Sydney or Melbourne. We had serial killers in Melbourne ... we had a couple of serial killer uprisings and so I knew the term. And here they'd had the serial killers, the Birnies, but nothing in recent memory apart from them. (Haw, personal communication, October 29, 2020)

He likened it to an enviousness between the west and east coasts of Australia, and even to a professional jealousy, particularly after Ivan Milat, an Australian serial killer who assaulted, imprisoned, robbed and subsequently murdered two men and five women, all backpackers, in New South Wales between 1989 and 1993. The media coverage of his capture, trial and his time incarcerated, until his death in 2019 has been fodder for books, documentaries and television crime specials.

Because everything in Perth has got to be better than Sydney or Melbourne. The attitudes I got here was even if there was a plane crash in Melbourne because of a fuel tank problem the different producers would ask, "Can you localise that story and make it a WA story?" and I'd say, "How?". "Well, it could it happen in WA, couldn't it?" they would ask. That "could've happened in WA story syndrome' was nearly everything. (Haw, personal communication, October 29, 2020)

This contest between major capital cities news media is not uncommon. Coulson and Lacy (1996) reviewed this competitiveness and found that a majority of journalists surveyed believed that direct competition promotes editorial diversity and competitiveness among journalists, but it can also lead to sensationalised news coverage.

The notion of sensationalism in news is not a novel concept. The use of sensational typification (Wood, 2005) is a common theme in media representation of crimes, particularly in cases such as this, where news coverage is used to gain attention or rally the public to action. Sensational typification of crime often involves super-violent predator-criminals, perpetuating horrific crimes that effect public outrage and whose deviance is attributed to purely individual flaws of that perpetrator.

In the case for the Claremont disappearances and murders, the catalyst for further state action and sensationalism was Ciara Glennon's disappearance, which injected a note of urgency from journalists and demands for safety from the public.

... and that's when the Ciara Glennon case erupted in the media. Basically, as soon as she disappeared, I'm thinking, another girl missing, bang. At that point, it became definitely a serial killer and I was really concerned about it. (Haw, personal communication, October 29, 2020) 
For this particular case, Haw along with several other journalists from competing newsrooms around Perth, took it upon themselves to get educated about serial killers. Haw was also the first journalist to use the phrase, 'serial killer', in a broadcast on 10 News First Perth on 6 August 1996. "They're looking for the remains of other missing women, possibly dumped here by a serial killer, including South Perth teenager Sarah Spiers who vanished six months ago."

We got into that a bit and then we started thinking... simultaneously, we started pushing the criminal psychology line... that's when the 'Mindhunter' stuff came in. When you look at, what they call, the victimology... (Haw, personal communication, October 29, 2020).

For Haw, his next move was to contact John Douglas directly. Douglas is a retired special agent from the FBI. He was one of the first criminal profilers in the world and has written many books on criminal psychology. He was also the inspiration, most recently, for David Fincher's Mindhunter (Fincher et al, 2017-2019) on Netflix. Douglas was more than happy to give Haw his views on what was details of the disappearances and murders as they stood in 1997. Access to the transcript for this interview with Rex Haw and John Douglas has been granted and will be used in the final study.

When asked in the interviews why he and other journalists felt the need to explore other elements of the case in more detail, there were a number of reasons, most importantly, because of a sense of public service:

I don't think we saw ourselves at the time as doing or if we did, we did it subconsciously. Because it was one of those things "What's in the public interest, rather than what's interesting for the public?" And we often found, it's almost like the news stories about the case became a public service rather than just news... (Haw, personal communication, October 29, 2020)

As Conboy and Eldridge (2017: 165) state, journalism has very much rested "on broad and noble-sounding commitments to service of the public". In this vein, the journalists have reconstructed the sense of responsibility to the public and its place within the public sphere. To take this position further, for some of the journalists, they felt they were a conduit for the families, particularly when WAPOL appeared to not be following up leads that journalists were fed from the public.

We were really working for the families. Not really working for the cops, so much as the families. (Mendez, personal communication, July 12, 2020)

While John Townsend was a general news journalist during his time covering the cases, he confirmed that the family connection was strong for some journalists:

Well, I would endorse that. I think that was the case... [name redacted] was more deeply involved through that entire period, so they were the number one point of contact who was dealing with the police as well, and with the family. I had a more peripheral role I guess; I was in and out and did press conferences and bits and pieces. They were more heavily involved with 
dealing with the families, and although I think I interviewed all of them, or had contact with all them, they were certainly far more deeply immersed in it. (Townsend personal communication, July 13, 2020).

I know we were as respectful as we could have been with the families in a pretty horrific time and having a lot to do with them too meant that there was a developed relationship between the reporters, who were the regular reporters and the family. (Townsend personal communication, July 13, 2020).

For Torrance Mendez, the feeling of just being an unbiased observer to the case, was impossible.

... for weeks and months afterwards, I would go around walking by the river and looking into the water wondering, if I would see anything that would be the remains of a body, and it's awful to say, and I spoke to other people that said the same, that they did that, people who would go out walking their dogs and they would look around and see if there were human remains... and it was simply awful. (Mendez, personal communication, July $12,2020)$

The journalists interviewed were also aware the "Glennon Factor" was moving this case into a level not seen before. The headline on the front page of The West Australian (Staff Reporters, 1997) the day after her body was found summed up the community mood: A State Mourns. The bolded, double barrelled headline was accompanied by the photo the community knew instantly; the picture of Ciara Glennon that had been released by her parents when she was reported as missing.

Sub headings "Ciara's body found in bush", and "Where the search ended" accompanied the most up to date news by staff reporters, but while the print gave details, the other additional photograph of a bird's eye view of police and forensic experts at the scene, gave a morbid view into what the investigators were dealing with. The other most obvious reflection was clear to the public also. This perpetrator had used the same manner to dispose of Ciara Glennon's body as he had with Jane Rimmer, despite them being 86 kilometres apart. No longer did the Perth community have another lost woman; we had a woman taken, taken off the streets of Claremont and the public were up in arms about it.

The measure of the case was graded according to the victim and victim's circumstances... that Ciara Glennon had the wherewithal to make this a sledgehammer inquiry. Sarah Spiers didn't, she was a girl shortly out of school, she was just 18, young, her body's never been found, do we really know what's happened to her? Jane Rimmer, she worked in a kindergarten, she wasn't a girl in the peak of society, she was a simple young woman on a night out, probably hoping for an early marriage in a short time and made a very silly decision on her own, but then we have Ciara Glennon where we have a woman of the world, who is experienced in travelling and has everything to look forward to, a life at the top and that is snatched away from her, and that simply should not happen, that is intolerable, we will not 
tolerate that kind of behaviour and it was made clear to the police. (Mendez, personal communication, July 12, 2020)

Without prompting, journalists also said that due to the personal wealth and influential connections of the Glennon family, the case was going to be at the forefront of police interest as well as having political clout. Two days after Ciara Glennon went missing in March 1997, then Premier of Western Australia, Richard Court, approved a reward of up to AUD\$250,000 (approximately US\$192,000) for information leading to the whereabouts of Sarah Spiers and Ciara Glennon, and a conviction for the murder of Jane Rimmer. In a press conference to the media at the time, Mr Court said the size of the reward - the largest monetary amount ever offered in Western Australian history reflected the community's concern.

Apparent political and business influence from the Glennon family gave her particular disappearance and murder an injection of funds that the family spearheaded, with large amounts of donations coming from high profile legal firms and business organisations being made available to WAPOL directly to help solve the mystery.

... the Glennon family marshalled the big end of town ... to raise the funding. But the message that money sent to the community was that this is high level crime, so high that the top person in the state is announcing it, and it was the Premier who made the announcement, it wasn't the Police ... and that itself was curious ... the lay public had the impression they're putting huge money, no stone is being left unturned, it's being afforded top priority, it [Ciara Glennon's disappearance] is more important than anything else. (Mendez, personal communication, July 12, 2020)

It was common knowledge amongst the journalists interviewed that the money raised was used to purchase a state-of-the-art DNA analysis machine, which WAPOL may have been able to afford but would, likely, have been subject to copious paperwork and government regiments, holding up the process of obtaining it. This machine and international crime experts and analysts were fast tracked onto this case with the help of this funding.

There are several other themes emerging from interview data that cannot be discussed here due to insufficient space, and the focus of this article on journalistic practices during the emergence of this news story. These other themes are likely to be addressed in my thesis and subsequent subsequent research as other interviews and analyses are completed. These themes include use of the word ' $\mathrm{girl} / \mathrm{s}$ ' to describe women in the case; differences in how disappeared or murdered women received different media treatment due to their circumstances or lifestyles; and, collective trauma propagated by news media.

\section{Conclusion: serial killing and ritualistic practices in Western Australian news}

With the sentencing of Bradley Edwards at the end of 2020, it is timely to reflect on journalistic practices in the emerging news coverage of this serial murder case that began 25 years ago. Informed by an archive of news reports on the case across this 
period and previous studies of journalism, this article has analysed data from interviews with three journalists who had contributed to the emerging news story on the case as well as the reasoning of a fourth journalist who refused to be interviewed but gave consent for discussion of their reasoning to be included in this article. Analysis of this information has provided the insights discussed above about the desire of journalists to take on additional 'roles' beyond the story teller; on why 'serial killer' entered news reports; on ritualistic practices in Western Australian newsroom culture around trying to outdo east coast news media; and, on why the disappearance and murder of Ciara Glennon led to Western Australia's Premier and other political and economic elites becoming involved in the case. This article sheds light on complex dynamics in and around the journalistic practices through which emerged a sensational and enduring news story on the murders and disappearances of women in Western Australia.

\section{References}

Australian Bureau of Statistics., 1996. 1996 Census Community Profiles: Perth. Retrieved from https://quickstats.censusdata.abs.gov.au/census_services/getproduct/census/1996/communitypr ofile/505?opendocument

Bell, C., 2009, 1992. Ritual theory, ritual practice. Oxford University Press.

Carey, J.W., 1975. A Cultural Approach to Communication. Communication 2: 1-22.

Christians, C. G., Glasser, T. L., McQuail, D., Nordenstreng, K., \& White, R. A., 2009. Normative theories of the media: Journalism in democratic societies. Urbana, IL: University of Illinois Press.

Cohen, S., 1972. Folk Devils and Moral Panics: The Creation of the Mods and Rockers. Routledge: London.

Conboy, M., Eldridge, S., 2017. Journalism and public discourse. In: Cotter, C. \& Perrin, D. (eds.) The Routledge Handbook of Language and Media. Routledge: New York.

Conley, D., Lamble, S., 2006. The Daily Miracle: An Introduction to Journalism.,3rd ed. Oxford University Press: Melbourne.

Coonfield, G., Huxford, J., 2009. News images as lived images: Media ritual, cultural performance, and public trauma. Critical Studies in Media Communication, 26.5: 457-479.

Couldry, N., 2005. Media rituals: Beyond functionalism. In: Rothenbuhler, E. \& Coman, M. (eds.) Media Anthropology. Sage: London.

Couldry, N., 2013. Media, Society, World: Social Theory and Digital Media Practice. John Wiley \& Sons.

Coulson, D., Lacy, S., 1996. Journalists' Perceptions of How Newspaper and Broadcast News Competition Affect Newspaper Content. Journalism and Mass Communication Quarterly, 73.2: $354-363$. 
Curran, J., Liebes, T., 2002. Media, Ritual and Identity. Routledge: London.

Douglas, J., Olshaker, M., 2017. Mindhunter: Inside the FBI's Elite Serial Crime Unit. Gallery Books: London.

Drewe, R., 2003. The Shark Net. Penguin Books: Melbourne.

Ecker, U., Lewandowsky, S., Chang, E., Pillai, R. (2014). The effects of subtle misinformation in news headlines. Journal of Experimental Psychology: Applied, 20.4: $323-335$.

Fincher, D., Penhall, J., Theron, C., (Executive Producers). (2017-2019). Mindhunter [TV series]. Denver and Delilah Productions; Netflix.

Gill, N., (2015, August 21). Where is the world's most remote city? The Guardian Australia. Retrieved from https://www.theguardian.com/cities/2015/aug/19/where-worlds-most-remotecity

Hall, S., Critcher, C., Jefferson, T., Clarke, J., Roberts, B., 1978. Policing the Crisis: Mugging, the State and Law \& Order. Palgrave Macmillan: New York.

Kitch, C., 2002. Anniversary Journalism, Collective Memory, and the Cultural Authority to Tell the Story of the American Past. The Journal of Popular Culture, 36: 44-67.

Kerr, T., 2015. To the Beach: Community Conservation and its Role in 'Sustainable Development'. UWA Publishing:

Mallabone, M., 1997, March 15. We’ve Had Enough. The West Australian, pg 1.

Marshall, D., 2007. The Devil's Garden: The Claremont Serial Killings. Random House: Australia.

McNeill, H., 2019, November 25. 'Enigma of the dark': Mystery of Claremont killings finally begins to unravel. WA Today. Retrieved from https://www.watoday.com.au/national/westernaustralia/enigma-of-the-dark-mystery-of-claremont-killings-finally-begins-to-unravel20191125-p53dz3.html

Mellado, C., 2015. Professional Roles in News Content: Six dimensions of journalistic role performance. Journalism Studies, 16: 596-614.

Morfesse, L., 1997, March 17. Woman Missing: Serial Killer Fear. The West Australian, pg 1.

Morton, R., 2005. Serial Murder: Multi-Disciplinary Perspectives for Investigators. Federal Bureau of Investigation: West Virginia.

Schlesinger, E., 2001. Is serial homicide really increasing? Journal of the American Academy of Psychiatry and the Law 29.3: 294-7.

Staff Reporters., 1997, April 4. A State Mourns. The West Australian, pg. 1. 
Statham-Drew, P., 2003. James Stirling: Admiral and Founding Governor of Western Australia. University of Western Australia Press: Crawley, WA.

Townsend., J., 1996, August 5. Maniac Feared as Crime List Grows. The West Australian, pg. 2.

Tuchman, G., 1978. Making News: A Study in the Construction of Reality. Free Press: New York.

Willnat, L., Weaver, D. H., Choi, J., 2013. The Global Journalist in the Twenty-first Century. Journalism Practice, 1-21.

Whish-Wilson, D., 2013a. Perth. University of New South Wales Press: Sydney.

Whish-Wilson, D., 2013b. Zero at the Bone. Viking: Melbourne.

Wood, J., 2005. In whose name? Crime victim policy and the punishing power of protection. NWSA Journal, 17.3: 1-17.

Wyatt, B., 2019. The WA economy: insights from the Treasurer [iLecture]. Retrieved from https://www.ceda.com.au/Events/Library/Past-Events1/W191101

Mary-Anne Romano is a doctoral candidate at Curtin University in Perth, Australia. Her currently research areas include journalism as practice, journalism and cultural memory, and how the media reports major crimes. As a former journalist who has worked and taught in the journalism field, she has completed an honours thesis and subsequent research work in the areas of moral panic, and the discrimination of women in newsrooms. In 2014, she was invited to take part in a student fellowship at Harvard University, where she was able to work with sociology, communication and journalism scholars to develop her current research specialities. 